\title{
Seroprevalence of Porcine Cysticercosis in Ludewa District, Njombe, Tanzania
}

\author{
Justine Daudi Maganira*, Norbet Ignas Hepelwa, Beda John Mwang'onde \\ Department of Biosciences, Sokoine University of Agriculture, Morogoro, Tanzania \\ Email: ^jdm878@sua.ac.tz
}

How to cite this paper: Maganira, J.D. Hepelwa, N.I. and Mwang'onde, B.J. (2018) Seroprevalence of Porcine Cysticercosis in Ludewa District, Njombe, Tanzania. Advances in Infectious Diseases, 8, 151-161. https://doi.org/10.4236/aid.2018.83014

Received: July 9, 2018

Accepted: September 16, 2018

Published: September 19, 2018

Copyright (c) 2018 by authors and Scientific Research Publishing Inc. This work is licensed under the Creative Commons Attribution International License (CC BY 4.0).

http://creativecommons.org/licenses/by/4.0/

\begin{abstract}
Small-scale subsistence farmers keep over $80 \%$ of the pigs in Tanzania as a backyard activity in mixed agro-ecological farming systems under unhygienic conditions that risk persistency of zoonoses including Taenia solium cysticercosis. Pig production and demand for pork has tremendously increased in Tanzanian townships and major cities. Rural areas are the main sources of pigs and pork and that the business is jeopardized by the presence of porcine cysticercosis (PC). Ludewa district is one of the PC unsurveyed sources of pork in townships and cities in Tanzania. The aim of this study was to assess the status of PC in Ludewa district, Tanzania. Auricular venous blood samples were collected from pigs in households for seroprevalence analysis of PC. In this study, $10.07 \%$ (95\% C.I. $06.86 \%$ - 14.47\%) of the collected 268 serum samples tested positive in the cysticercosis antigen enzyme-linked immune-sorbent (Ag ELISA) assay. PC infection rate was $10.71 \%(\mathrm{n}=24)$ in adult pigs and $6.82 \%(\mathrm{n}=3)$ in piglets. PC infection between adult pigs and piglets was not statistically significant ( $O R=0.6108$; 95\% C.I. $0.1125-2.1575)$, $\mathrm{p}=0.5877)$. The highest and lowest number of PC positive cases were detected in Mapogoro ( $\mathrm{n}=16,13.91 \%, 95 \%$ C.I. 8.41 - 21.91) and Ludewa Mjini $(\mathrm{n}=6$, $6.67 \%$, 95\% C.I. 2.74 - 14.50) villages respectively. The Chi-Square test indicated no significant statistical difference in the status of PC infection between the three villages $(p=0.1881)$ involved in this study. PC prevalence in the study area indicates the presence of $T$. solium tapeworm human carriers and environmental contamination by $T$. solium eggs. This is the first survey to reveal the prevalence of PC in Ludewa district and therefore calls for further studies on the magnitude, economic and public health impacts of taeniasis and cysticercosis in the human population. The result of this study is also important in the determination of effective control measures of cysticercosis.
\end{abstract}

\section{Keywords}

Porcine Cysticercosis, Taenia solium, Seroprevalence, Ludewa, Njombe, 


\section{Introduction}

For many reasons, there is limited information on the burden of Taenia solium cysticercosis, a zoonotic disease between man and pigs, in endemic regions. The disease greatly impacts food security and safety, public and veterinary health and finally economies of developing endemic countries. The adult parasite causes taeniasis in humans while its larval form causes cysticercosis in both humans and pigs [1]. In the piggery industry, infection by the parasite (porcine cysticercosis (PC)) denies people from pork protein and causes huge economic loss because of veterinary costs, reduced pork production and total condemnation of PC detected pork carcases [2]. Infection of the larval form in human (human cysticercosis (HC)), among other parts of the body, in the central nervous system (CNS) results into neurocysticercosis which is the major cause of acquired epilepsy in T. solium endemic areas [3] [4]. Humans may harbour adult pork tapeworms in the intestine and hence taeniasis for many years without significant health symptoms. Following consumption of uncooked or undercooked pork infected with the larval stage of $T$. solium known as Cysticercus cellulosae [1] [5] [6] [7], the larvae develops into adult worm with which human can harbour the parasite for over 20 years if untreated and remains a good carrier of the parasite and therefore source of environmental contamination. On the other hand, humans contract cysticercosis by ingesting $T$. solium eggs from contaminated food, drinking water or hands after an unhygienic attendance of a natural call or indiscriminate defaecation [8] [9] [10] [11]. As in humans, pigs contract cysticercosis following ingestion of feed-stuff or water or human faeces containing $T$. solium eggs from pork tapeworm carriers or ingestion of the eggs from contaminated environmental soils [10] [11]. With this route of transmission, infection by the larval form of $T$. solium spares neither ethnic nor religious group [12] [13]. Because of globalization and worldwide tourism, like Catholics: the Orthodox Jews, Muslims, Seventh-Day Adventists and vegeterians are all at risk of infection by the larval form of $T$. solium.

Pig production, especially in rural areas, has increased in the past few years because of population growth and scarcity of grazing land for ruminants [7]. The increase in piggery industry has also been due to quick and high returns accrued from investing in pig production as compared to investing in ruminants as well as the high demand for pork in townships, urban and cities [6] [7]. The increase in pig production in many rural areas of developing countries with high rates of poverty and ignorance mediates the occurrence and persistence of $T$. solium cycle. As the number of PC reports escalates in sub-Saharan African countries indicating prevalence ranging from as low as $0.12 \%$ to over $50 \%$ [2] [14] [15] [16] [17] [18], many rural areas of Tanzania where the majority of the pigs 
are farmed [6] in traditional systems coupled with poor hygiene and sanitation remain unsurveyed. Thus, the status of PC from various rural areas, which also have high production of pigs in Tanzania, is inadequately recorded. Survey studies in a few Tanzania rural areas have reported the prevalence of PC as high as 33\% [15] [19] [20] with around 3 million USD being lost due to PC [21]. The persistence of the disease further inhibits exportation of pork that negatively affects foreign exchange. Therefore, the knowledge of the prevalence and risk factors of zoonotic parasites such as T. solium cysticercosis and subsequently their associated economic and public health impacts is important in order to determine effective prevention and control measures. The information from this study is useful to minimize or prevent future cases of $T$. solium cysticercosis in Tanzania and elsewhere in endemic regions. This study reports for the first time the persistence and prevalence of PC in Ludewa district, Tanzania.

\section{Materials and Methods}

\subsection{Study Area}

This study was conducted in Ludewa district between November 2017 and March 2018 (Figure 1). Ludewa district is among the districts forming the Njombe Region in Tanzania [22] and lies between latitudes $10^{\circ} 06^{\prime} \& 10.10^{\circ} 00^{\prime} \mathrm{S}$ and longitudes $34^{\circ} 45^{\prime} \& 34.68^{\circ} 00^{\prime} \mathrm{E}$. Njombe region (Latitude $8^{\circ} 40^{\prime} \& 10^{\circ} 32^{\prime} \mathrm{S}$; longitude $33^{\circ} 47^{\prime} \& 35^{\circ} 45^{\prime} \mathrm{E}$ ) was formerly part of Iringa region until March 2012 when it was gazetted as a new and separate region [22]. Lake Nyasa borders Ludewa district to the southwest, Kyela (in Mbeya region) and Makete to the west, Njombe district to the north while Ruvuma region borders Ludewa district
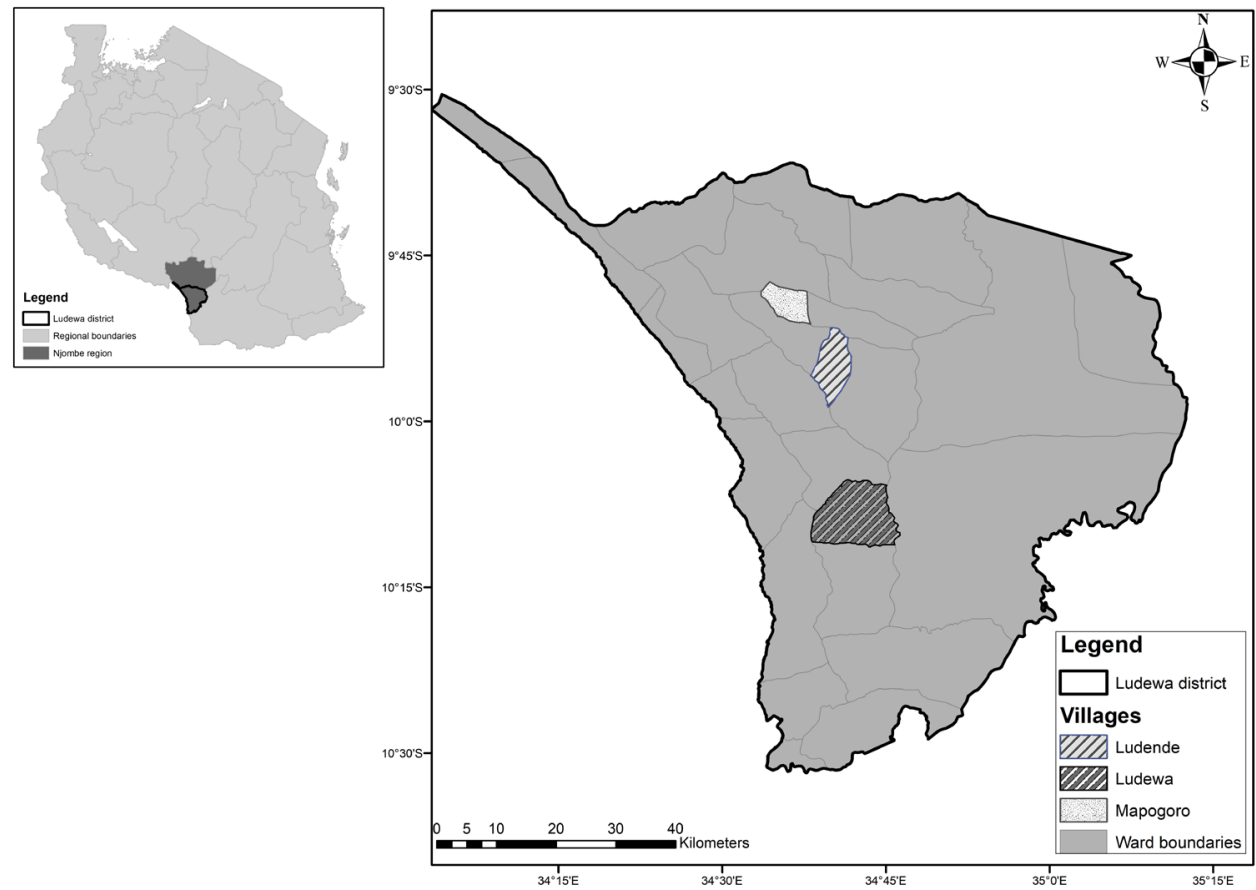

Figure 1. Map of Tanzania showing surveyed villages in Ludewa district. 
to the southeast. According to the 2007-2008 National Sample Census of Agriculture, the district had a population of 23,998 pigs with an average of two pigs per household [23]. According to 2012 Population and Housing Census, the population of Ludewa district was 133,218 people in 2012 and projected to reach 138,618 people in the year 2017 [24]. The major economic activities in Ludewa district include fishing, livestock keeping and small-scale subsistence farming. Ludewa district was of interest because to the best of our knowledge there was no any published PC survey study despite the fact that the district is one of the sources of pigs and therefore pork in townships, urbans and Dar es Salaam City.

\subsection{Study Design and Sample Size Estimation}

A cross-sectional survey was conducted to investigate the prevalence of PC in Ludewa district. One village was selected randomly from each of the three wards involved in this study (Milo and Ludende wards from about 2600 m.a.s.l and Ludewa ward with about 1500 m.a.s.l). Names of villages from each ward were written in a piece of paper, folded and mixed before they were thrown on a table to pick one piece of paper with a village name for survey. The process was repeated in each of the selected three wards. Ludewa Mjini (Ludewa ward), Ludende (Ludende ward) and Mapogoro (Milo ward) villages were selected for this study. The selection of households for inclusion in the study was also random; however, the presence of pigs was taken into account. An average of 25 households per village participated in this study. The prevalence level of PC was determined from sera recovered from blood samples and the study was biased to different age groups of pigs and sources. A maximum of 6 pigs were randomly chosen from each of the households participating in this study. Generally, 6 pigs were sampled in households with both litters and sounder of swine. A random sampling of a maximum of 3 piglets was deployed in litters of more than 3 piglets, similarly to sounder of swine at any one participating household. In households with 3 or less adult pigs and or piglets, all were sampled. The formula $\mathrm{n}=$ $\mathrm{Z}^{2} \mathrm{PQ} / \mathrm{L}^{2}$ [25] was used to estimate the sample size, where $\mathrm{n}$ is the number of pigs, $\mathrm{P}$ is an estimated prevalence level of $\mathrm{PC}$ in the study area, $\mathrm{Z}$ is the score of the desired confidence interval (95\%), Q = $1-\mathrm{P}$, and $\mathrm{L}$ is the permissible error of estimation (5\%). Based on this formula, the estimated minimum sample size of pigs was 113 (that is $n=1.96^{2} \times 0.08 \times 0.92 / 0.05^{2}$ ). Maximization of the sample size to 170 was done according to Yohana and others [26]. Using random selection of households and pigs, 268 serum samples were collected.

\subsection{Data Collection}

About 3 - $4 \mathrm{ml}$ was drawn from auricular venous blood of pigs using hypodermic syringes and kept in a $5 \mathrm{ml}$ Becton Dickinson (BD) vacutainer tubes. Each syringe was used in one pig and once that after withdraw of blood, the syringe used was disposed. The verbal informed consent was sought from each of heads of the households (pig owners) participating in the study. The age limit for in- 
clusion of pigs in the study was 3 to 5 months for piglets and 6 months or above for adults. A random sampling of a maximum of 3 piglets was deployed in litters of more than 3 piglets, similary to sounder of swine at any one participating household. Therefore, at most six pigs were sampled in households with both litters and sounder of swine. In households with three or less pigs and or piglets, all were sampled. Blood samples were temporarily stored at $4^{\circ} \mathrm{C}$ in a cooler box during data collection. The recovery of serum samples were done by centrifuging blood samples for 10 minutes at $3500 \mathrm{rpm}$. Clear serum samples were stored in adequately labeled $1.8 \mathrm{ml}$ cryogenic vials at $-20^{\circ} \mathrm{C}$ before further analysis for PC.

\subsection{Laboratory and Statistical Data Analysis}

In the laboratory, cysticercosis antigen enzyme-linked immune-sorbent (apDia Cysticercosis antigen ELISA) was used in qualitative determination of serum samples for PC according to manufacturer's protocol. Briefly, pretreated serum and control samples were added to the B158C11A10 monoclonal antibody coated wells for incubation. The incubation at $37^{\circ} \mathrm{C}$ for 15 minutes while shaking $800 \mathrm{rpm}$ allowed circulating antigens from viable cysticerci to bound to the wells. After removing all unbound sample materials by washing the microtiter strips using phosphate buffered solution, the antigen-antibody complex in each well was detected with B60H8A4 monoclonal antibodies. Before the absorbance values were determined at $450 \mathrm{~nm}$, the enzymatic reaction was stopped by adding $0.5 \mathrm{M} \mathrm{H}_{2} \mathrm{SO}_{4}$ solution. All statistical analyses were performed in $\mathrm{R}$ version 3.4.3 [27]. The prevalence of PC was computed using descriptive statistics. The Chi-Square test of independence was used to compare PC differences between villages and pig age groups.

\section{Results}

Two hundred and seventy one pigs from various households in the three villages in Ludewa district were involved in this study (Table 1). One blood sample for serum recovery was collected from each pig after obtaining informed oral consent of the pig owners. Three samples were excluded from the statistical analysis because of either, a microplate reader could not determine the absorbance value (optical density, OD) at $450 \mathrm{~nm}$ wavelength or the results were doubtful with $\mathrm{Ag}$ index falling between 0.8 and 1.3. Because it was not possible to have freshly drawn blood, the three serum samples were stored at $-20^{\circ} \mathrm{C}$ to be retested later using another convenient method. The number of households in the villages involved in this study differed depending on the availability of pigs. Of the total number of households included in this study, Ludende village had the lowest ( $\mathrm{n}$ $=42,25.77 \%)$ followed by Ludewa Mjini village $(\mathrm{n}=57,34.97 \%)$ while Mapogoro village had the highest $(\mathrm{n}=64,39.26 \%)$. The number of pigs statistically examined was lowest in Ludende village $(\mathrm{n}=63,23.51 \%)$ and highest in Mapogoro village $(\mathrm{n}=115,42.91 \%)$. Of the 268 statistically analysed serum samples, 224 were adult pigs $(83.58 \%$, 95\% C.I. $78.47 \%$ - 87.70\%) while piglets were 44 
Table 1. Prevalence of porcine cysticercosis by Cysticercosis Ag ELISA test in three villages in Ludewa District.

\begin{tabular}{ccccccccc}
\hline & \multicolumn{3}{c}{ Examined Pigs } & \multicolumn{5}{c}{ Positive Pigs } \\
\hline Village & Adults & Piglets & Total & Adults & Piglets & Total & $\%$ & $95 \%$ C.I. \\
\hline Ludende & 45 & 18 & 63 & 4 & 1 & 5 & 7.94 & $2.96-18.27$ \\
Ludewa & 78 & 12 & 90 & 5 & 1 & 6 & 6.67 & $2.74-14.50$ \\
Mapogoro & 101 & 14 & 115 & 15 & 1 & 16 & 13.91 & $8.41-21.91$ \\
Total & 224 & 44 & 268 & 24 & 3 & 27 & 10.07 & $06.86-14.47$ \\
\hline
\end{tabular}

(16.42\%, 95\% C.I. $12.30 \%-21.53 \%)$. Generally, among the 268 analysed serum samples, 27 (10.07\%, 95\% C.I. 06.86\% - 14.47\%) tested positive while 241 (89.93\%, 95\% C.I. 85.53 - 93.14) tested negative for porcine cysticercosis Ag ELISA (Table 1). The number of serum samples, which tested positive for PC in Ludende, Ludewa Mjini and Mapogoro villages, were 5 (7.94\%, 95\% C.I. 2.96 18.27), 6 (6.67\%, 95\% C.I. $2.74-14.50)$ and 16 (13.91\%,95\% C.I. $8.41-21.91)$ respectively. The difference in PC status among the three villages was not significant by the Chi-Square test ( $\mathrm{p}$-value $=0.1881)$. Between adult and piglet age categories the infection status was $10.71 \%(24 / 224)$ and $6.82 \%(3 / 44)$ respectively. The Fisher's Exact Test indicated no significant difference of PC infection between adult pigs and piglets $(\mathrm{OR}=0.6108$; 95\% C.I. $0.1125-2.1575), \mathrm{p}=$ 0.5877).

\section{Discussion}

Two hundred sixty eight (268) serum samples from rural pigs in three villages were used for qualitative analysis of PC prevalence in Ludewa district in Njombe region located in the southern highlands in Tanzania. To the best of our knowledge, this publication constitutes the first study on PC in Ludewa district. The results from this study indicate the prevalence of PC to be $10.07 \%$. What is reported in the present study is similar to that reported in Mbeya Region [28], one of the regions forming the southern highlands in Tanzania. There has also been a more or less similar report on PC in Uganda [14]. On the other hand, PC status determined in this study is three times less than what is reported in a similar study conducted in Nyasa District in Ruvuma region which borders Ludewa district to the southeast [15]. High prevalence of PC in the Eastern African region is also reported in Kenya [16].

Previous survey on PC by [20] using antemortem and postmortem examination in two districts in Iringa region located to the north of Njombe Region recorded prevalence ranging between $7.6 \%$ and $8.4 \%$ while the same study also recorded an overall prevalence of $16.9 \%$ in two Districts in Ruvuma region. The prevalence of PC in Ludewa District in Njombe region reported in the present study and recent reports [15] in Ruvuma and Mbeya region [15] [28] indicate the persistence of $T$. solium infection in the southern highlands regions of Tanzania where majority of the pigs are kept under free and semi intensive systems 
of keeping pigs. The epidemiology of taeniasis-cysticercosis indicates that whenever pigs are infected with $T$. solium cysticercosis, some members of the community are infested with adult $T$. solium. T. solium human carriers have the greatest potential for contaminating the environment with the parasite eggs when there is poor hygiene and sanitation. The Differences in the prevalence of porcine cysticercosis in the southern highland regions (Iringa, Njombe, Ruvuma and Mbeya) thus may indicate differences in T. solium eggs environmental contamination as well as taeniasis in the human population. Therefore, the persistent of PC in the southern highlands calls for control and prevention strategies.

The infection rate of PC between adult pigs and piglets was determined at $10.71 \%$ and $6.82 \%$ respectively; however, this difference was not statistically significant ( $p=0.5877)$. In the majority of the households, piglets were confined reducing the likelihood of encountering human faeces infected with pork tapeworm eggs. On the other hand, adult pigs, from most of the households, were seen freely roaming and scavenging for food in the streets increasing the risk of infection by pork tapeworm from infected indiscriminately human faeces. The age and size of the piglets may also be a factor preventing them from breaking their pens as compared to adult pigs which because of the age and size attained they may be energetic enough to break apart their pens and escape away to scavenge and hence the observed differences in PC infection rate. It should be noted in the first place that most pig owners, as a way of curbing food shortage, willingly release their pigs to scavenge for food.

The prevalence of PC in Mapogoro village was high $(n=16,13.91 \%)$ as compared to the rest of the villages, Ludende and Ludewa Mjini, which recorded 7.94\% $(\mathrm{n}=5)$ and $6.67 \%(\mathrm{n}=6)$ respectively. Although Mapogoro village had the highest number of pigs ( $\mathrm{n}=115,42.91 \%$ ) recruited in this study, it had also most of the pigs that were observed roaming while most pigs specifically in $\mathrm{Lu}$ dewa Mjini village were confined because part of this village is slowly turning into a town centre and therefore sanitation facilities are available and a bit improved. Rural areas with extensive free range pig keeping system with inadequate hygiene and sanitation facilities have been reported to have high prevalence of T. solium cysticercosis [6] [18] [26] [29] because pigs and humans gain easy access to human faeces which may be contaminated by $T$. solium eggs [6].

The prevalence of PC in the surveyed rural areas of Ludewa District indicates the presence of pork tapeworm human carriers accompanied with poor sanitation and hygiene. This is to say whenever PC persists; there are tapeworm carriers who contaminate environment through open defecation. Presence of $T$. solium human carriers and a possibility of $T$. solium eggs environmental contamination pose health risks to residents in Ludewa and other areas receiving drinking water or food items that may be contaminated by $T$. solium eggs or consuming pork originating from Ludewa given inadequate meat inspection.

\section{Concluding Remarks}

For the first time, the prevalence of PC was assessed and recorded in the study 
area. Although the results recorded, indicate about three times lower prevalence compared to what was reported in Nyasa District in Ruvuma, a region bordering Njombe region, it is an indication of the existing risks of $T$. solium infection to both pig and human populations in the vicinity and faraway. Because the treatment of $T$. solium cysticercosis is difficult and with varying success [30] enacting prevention measures in the study rural area is of primary importance. The adoption of modern pig farming systems, provision of health education, community campaign on comprehensive hygiene, effective routine use of sanitary facilities, proper and strict meat inspection as well as adequate pork cooking, should be part and parcel of $T$. solium prevention strategies. With the aim to remove the pork tapeworm zoonotic parasite from the infection cycle and hence preventing the occurrence of new T. solium cysticercosis infection cases, the human population in the study area should also be freed of taeniasis. This may be preceded by exploring the status of $T$. solium cysticercosis and taeniasis infection in the human population.

\section{Limitation of the Study}

This study was limited to villages that keep pigs under semi-intensive and free range systems in Ludewa District. It was further limited by geographical location based on altitude as some research villages were from as low as 1500 m.a.s.l and others from about 2600 m.a.s.l.

\section{Acknowledgements}

The authors acknowledge the support of the Department of Biosciences (DoB) in the Solomon Mahlangu College of Science and Education (SM-CoSE), the College of Veterinary Medicine and Biomedical Sciences (CVMBS) of the Sokoine University of Agriculture (SUA), St. Luke's Milo Hospital (St. LMH) and Ludewa District Hospital (LDH) in Ludewa District. The authors would also like to acknowledge the support and services offered by the following people: Dr. Benedict Sandagila (Medical Doctor Incharge, St. LMH), Mr. James Mtweve (Laboratory Technologist, St. LMH), Mr. Mgaya (Laboratory Technologist, LDH), Dr. Luthol Kilimba (Medical Doctor Incharge, LDH), Ms. Frederica Laswai (Livestock Extension Officer, Mapogoro village, Ludewa), Marco Mhagama (District Livestock and Fisheries Officer (DLFO), Ludewa District), George Makingi (Laboratory Technologist, CVMBS, SUA) and Amina Hamad (Department of Geography and Environmental Studies, SUA).

\section{Authors Contributions}

J.D.M. (Sokoine University of Agriculture) designed the study. N.I.H. and B.J.M. (Sokoine University of Agriculture) carried out field data collection. J.D.M. and N.I.H. carried out laboratory data analysis. J.D.M. carried out statistical data analysis, drafted the manuscript and interpreted the results. B.J.M revised the manuscript. All the authors (J.D.M., N.I.H. and B.J.M.) approved the final ver- 
sion of the manuscript.

\section{Conflicts of Interest}

The authors affirm that there is no competing interest among them in the writing of this article.

\section{References}

[1] Liu, D. (2013) Molecular Detection of Human Parasitic Pathogens. Taylor \& Francis Group, Boca Raton.

[2] Praet, N., Speybroeck, N., Manzanedo, R., Berkvens, D., Nforninwe, D.N., Zoli, A., Quet, F., Preux, P.M., Carabin, H. and Geerts, S. (2009) The Disease Burden of Taenia solium Cysticercosis in Cameroon. PLoS Neglected Tropical Diseases, 3, 1-8. https://doi.org/10.1371/journal.pntd.0000406

[3] Coral-Almeida, M., Rodríguez-Hidalgo, R., Celi-Erazo, M., García, H.H., Rodríguez, S., Devleesschauwer, B., Benítez-Ortiz, W., Dorny, P. and Praet, N. (2014) Incidence of Human Taenia solium Larval Infections in an Ecuadorian Endemic Area-Implications for Disease Burden Assessment and Control. PLoS Neglected Tropical Diseases, 8, e2887. https://doi.org/10.1371/journal.pntd.0002887

[4] Mwape, K.E., Blocher, J., Wiefek, J., Schmidt, K., Dorny, P., Praet, N., Chiluba, C., Schmidt, H., Phiri, I.K., Winkler, A.S. and Gabriël, S. (2015) Prevalence of Neurocysticercosis in People with Epilepsy in the Eastern Province of Zambia. PLoS Neglected Tropical Diseases, 9, 1-15. https://doi.org/10.1371/journal.pntd.0003972

[5] Eom, K.S. (2006) What Is Asian Taenia? Parasitology International, 55, 137-141. https://doi.org/10.1016/j.parint.2005.11.022

[6] Ngowi, H.A., Phiri, I.K., Afonso, S., Matenga, E., Boa, M.E., Mukaratirwa, S., Githigia, S., Maingi, N., Lubega, G.W., Kassuku, A., Michael, L., Siziya, S., Krecek, R.C., Noormahomed, E. and Vilhena, M. (2004) Taenia solium Cysticercosis in Eastern and Southern Africa-An Emerging Problem in Agriculture and Public Health. Southeast Asian Journal of Tropical Medicine and Public Health, 35, 266-270.

[7] Phiri, I.K., Ngowi, H., Afonso, S., Matenga, E., Boa, M., Mukaratirwa, S., Githigia, S., Saimo, M., Sikasunge, C., Maingi, N., Lubega, G.W., Kassuku, A., Michael, L., Siziya, S., Krecek, R.C., Noormahomed, E., Vilhena, M., Dorny, P. and Willingham, A.L. (2003) The Emergence of Taenia solium Cysticercosis in Eastern and Southern Africa as a Serious Agricultural Problem and Public Health Risk. Acta Tropica, 87, 13-23. https://doi.org/10.1016/S0001-706X(03)00051-2

[8] Chacha, M., Julius, T. and Nkwengulila, G. (2013) Environmental Contamination by Taenia Eggs in Iringa Rural District, Tanzania. Open Environmental Engineering Journal, 6, 1-6. https://doi.org/10.2174/1874829501306010001

[9] Mwanjali, G., Kihamia, C., Kakoko, D.V., Lekule, F., Ngowi, H., Johansen, M.V., Thamsborg, S. and Willingham, A.L. (2013) Prevalence and Risk Factors Associated with Human Taenia Solium Infections in Mbozi District, Mbeya Region, Tanzania. PLoS Neglected Tropical Diseases, 7, 1-8. https://doi.org/10.1371/journal.pntd.0002102

[10] Johansen, M.V., Trevisan, C., Braae, U.C., Magnussen, P., Ertel, R.L., Mejer, H. and Saarnak, C.F.L. (2014) The Vicious Worm-A Computer-Based Taenia solium Education Tool. Trends in Parasitology, 30, 372-374. https://doi.org/10.1016/j.pt.2014.06.003

[11] Mwang'onde, B.J., Nkwengulila, G. and Chacha, M. (2014) The Risk Factors for 
Human Cysticercosis in Mbulu District, Tanzania. Onderstepoort Journal of Veterinary Research, 81, 1-5. https://doi.org/10.4102/ojvr.v81i2.719

[12] Schantz, P.M. Moore, A.C., Munoz, J.L, Hartman, B.J., Schaefer, J.A., Aron, A.M., Persaud, D, Sarti, E., Wilson, M. and Flisser, A. (1992) Neurocysticercosis in an Orthodox Jewish community in New York City. New England Journal of Medicine, 327, 692-695. https://doi.org/10.1056/NEJM199209033271004

[13] Flisser, A., Sarti, E., Lightowlers, M. and Schantz, P. (2003) Neurocysticercosis-Regional Status, Epidemiology, Impact and Control Measures in the Americas. Acta Tropica, 87, 43-51. https://doi.org/10.1016/S0001-706X(03)00054-8

[14] Waiswa, C., Fèvre, E.M., Nsadha, Z., Sikasunge, C.S. and Willingham, A.L. (2009) Porcine Cysticercosis in Southeast Uganda-Seroprevalence in Kamuli and Kaliro Districts. Journal of Parasitology Research, 1, 1-5. https://doi.org/10.1155/2009/375493

[15] Shonyela, S.M., Mkupasi, E.M., Sikalizyo, S.C., Kabemba, E.M., Ngowi, H.A. and. Phiri, I. (2017) An Epidemiological Survey of Porcine Cysticercosis in Nyasa District, Ruvuma Region, Tanzania. Parasite Epidemiology and Control, 2, 35-41. https://doi.org/10.1016/j.parepi.2017.09.002

[16] Thomas, F.L., Harrison, L.J.S., Toye, P., Glanville, W.A., Cook, E.A.J., Wamae, C.N. and Fèvre, E.M. (2016) Prevalence of Taenia solium Cysticercosis in Pigs Entering the Food Chain in Western Kenya. Tropical Animal Health and Production, 48, 233-238. https://doi.org/10.1007/s11250-015-0949-6

[17] Krecek, R.C., Michael, L.M., Schantz, P.M., Ntanjana, L., Smith, M.F., Dorny, P., Harrison, L.J.S., Grimm, F., Praet, N. and Willingham, A.L. (2008) Prevalence of Taenia solium Cysticercosis in Swine from a Community-Based Study in 21 Villages of the Eastern Cape Province, South Africa. Veterinary Parasitology, 154, 38-47. https://doi.org/10.1016/j.vetpar.2008.03.005

[18] Ngowi, H.A., Mukaratirwa, S., Lekule, F.P., Maingi, N., Waiswa, C., Sikasunge, C., Afonso, S., Sumbu, J., Penrith, M.L. and Willingham, A.L. (2013) Agricultural Impact of Porcine Cyisticercosis in Africa-A Review. Intech Open Science, 77-92.

[19] Braae, U.C., Magnussen, P., Lekule, F., Harrison, W. and Johansen, M.V. (2014) Temporal Fluctuations in the Seroprevalence of Taenia solium Cysticercosis in Pigs in Mbeya Region, Tanzania. Parasites and Vectors, 7, 1-7. https://doi.org/10.1186/s13071-014-0574-7

[20] Boa, M.E., Mahundi, E.A., Kassuku, A.A., Willingham, A.L. and Kyvsgaard, N.C. (2006) Epidemiological Survey of Swine Cysticercosis Using Antemortem and Postmortem Examination Tests in the Southern Highlands of Tanzania. Veterinary Parasitology, 139, 249-255. https://doi.org/10.1016/j.vetpar.2006.02.012

[21] Trevisan, C., Devleesschauwer, B., Schmidt, V., Winkler, A.S., Harrison, W. and Johansen, M.V. (2017) The Societal Cost of Taenia solium Cysticercosis in Tanzania. Acta Tropica, 165, 141-154. https://doi.org/10.1016/j.actatropica.2015.12.021

[22] Staff (2012) Tanzania-State Gazettes New Regions, Districts. Daily News, Dar es Salaam, March 9, 1-2.

[23] National Bureau of Statistics (2012) National Sample Census of Agriculture-Socio-Economic Profile of Iringa Region, United Republic of Tanzania.

[24] National Bureau of Statistics (2014) Population and Housing Census-Basic Demographic and Socio-Economic Profile, United Republic of Tanzania.

[25] Thrusfield, M. (2008) Veterinary Epidemiology. Black Well Science, Oxford.

[26] Yohana, C., Mwita, M. and Nkwengulila, G. (2013) The Prevalence of Porcine Cys- 
ticercosis and Risk Factors for Taeniasis in Iringa Rural District. International Journal of Animal and Veterinary Advances, 5, 251-255.

[27] R Core Team (2017) R-A Language and Environment for Statistical Computing. R Foundation for Statistical Computing. R Version 3.4.3, Vienna Austria.

http://www.R-project.org

[28] Kabululu, M.L., Ngowi, H.A., Kimera, S.I., Lekule, F.P., Kimbi, E.C. and Johansen, M.V. (2015) Risk Factors for Prevalence of Pig Parasitoses in Mbeya Region, Tanzania. Veterinary Parasitology, 212, 460-464. https://doi.org/10.1016/j.vetpar.2015.08.006

[29] Mwang'onde, J.B., Chacha, M. and Nkwengulila, G. (2012) The Serological Survey for Human Cysticercosis Prevalence in Mbulu District, Tanzania. Advances Infectious Diseases, 2, 62-66. https://doi.org/10.4236/aid.2012.23009

[30] World Health Organization (2007) Global Plan to Combat Neglected Tropical Diseases 2008-2015. World Health Organization, Geneva. 